Acta Theriologica 42 (1): 55-70, 1997.

PL ISSN 0001-7051

\title{
A quantitative study of diet in three species of rodents in natural and irrigated savanna fields
}

\author{
Safianu RABIU and Robert K. ROSE
}

Rabiu S. and Rose R. K. 1997. A quantitative study of diet in three species of rodents in natural and irrigated savanna fields. Acta Theriologica 42: 55-70.

During July, 1990 - June, 1992 we collected stomach contents of necropsied rodents that totalled 494 Arvicanthis niloticus (Desmarest, 1822), 356 Mastomys natalensis (Smith, 1834) and 273 Tatera valida (Wroughton, 1906) from natural, savanna fields in Nigeria, and 528 Arvicanthis and 367 Mastomys from nearby irrigated fields, where Tatera was never trapped. The materials were processed and microscopically analyzed to determine patterns of diet selection. Sites were sampled for vegetative cover and rodent food resources. More than $90 \%$ of the stomach materials could be identified to one of four categories: dicots (vegetative), monocots (vegetative), seeds, and insects. Seeds constituted approximately $50 \%$ by mass of foods consumed by all species in both sites during the rains. Mastomys (in both sites) and Tatera maintained the same levels of seed intake year around. Unlike Mastomys, the amount of seeds consumed by Arvicanthis was enhanced by irrigation. In both sites during the rains, monocots and insects made up $12-46 \%$ and $14-26 \%$ of the rodents diet respectively, but their importance diminished in the natural site during the dry seasons. Tests of MANOVA indicated significant species differences and effects of site, season and their interactions on foods selected. A few plant species dominated the vegetative cover, and dramatic differences in the quality of seasonal herbage were observed.

Department of Biological Sciences, Old Dominion University, Norfolk, Virginia 23529-0266 , U.S.A.

Key words: Arvicanthis, Mastomys, Tatera, rodent's diet, Nigeria

\section{Introduction}

In the natural and agricultural fields of savanna northern Nigeria three species of small mammals, namely Arvicanthis niloticus (Desmarest, 1822), Mastomys natalensis (Smith, 1834) and Tatera valida (Wroughton, 1906), are commonly found together, sometimes with one or more other species of rodents. They feed on local crops and cause some damage (Funmilayo and Akande 1977, Happold 1987). The three species are among the most widespread in West Africa (Rosevear 1969), though Arvicanthis may be localized in its distribution to crop fields and moist areas. In general, the distribution of the three rodents in Nigeria decreases 
from the savannas of the north to the forests of the south. In the south, they are restricted to areas close to human habitation in the "derived savanna" (Happold 1987). Despite this commonness, little information on their food habits and feeding ecology from these areas is known. Ecological notes in Rosevear (1969) and Happold (1987) are mostly generalized; the latter refers to some unpublished data on the food selection of Tatera in Nigeria from areas north of latitude $10^{\circ} \mathrm{N}$. Recently, Rabiu and Fisher (1989) document the diet of Arvicanthis from northern Nigeria. With these exceptions most dietary studies in the same or related taxa have been conducted in other parts of Africa, eg Swanepoel (1980) in southern Africa, Hubert et al. (1981) in Senegal, and Field (1975) and Taylor and Green (1976) in eastern Africa.

Most recent studies and some older ones on techniques of rodent dietary analysis, notably Williams (1959), Hansson (1971), Perrin (1980), Bar et al. (1984), and Neal (1984), have used some form of microscopic method of food particle examination. Still other studies have relied on visual assessment of the composition of gut contents. In the majority of these studies, food items consumed vary with seasonal and local availability, and include insects and other animal material, monocotyledonous and dicotyledonous vegetation (monocots and dicots), and often some weed seeds, cereals and grains. In fact, part of the economic importance attached to some species, particularly Arvicanthis and Mastomys, relates to their depredation of, and damage to, food crops (Taylor 1968, Taylor and Green 1976, Poulet and Poupon 1978).

The rationale for many rodent diet studies (including the present one) lies in the importance of food in assessing the rodents' biological roles in natural and cultivated ecosystems and the importance of food on such ecological factors as breeding and population dynamics (S. Rabiu and R. K. Rose, in prep). In addition, much of the research involving seasonal changes of diets of small mammals in Africa has been on the influence and regulatory role of diet in reproduction (Sheppe 1972, Neal 1977, Ghobrial and Hodieb 1982, Neal 1982, Delany 1986, Delany and Monro 1986, Leirs et al. 1989).

The objectives in the present study were to make a quantitative analysis of food items consumed by three species of rodents, namely the Nile rat A. niloticus, the multimammate rat $M$. natalensis and the savanna gerbil $T$. valida, with a view to determining their seasonal food selection in the natural grasslands and irrigated fields of northern Nigeria. Our two-year study was designed to cover two rainy and two dry periods, thus making it possible to compare seasonal changes in the dietary selection of the species. This paper also documents the habitat conditions and potential foods available during different seasons in the natural and irrigated sites. We learned that seeds were the most important food type, even though the species differed somewhat in their food selection in both natural and irrigated sites. 


\section{Methods}

\section{Study areas}

The study sites in both natural (Bagauda-Gwarmai) and irrigated (Kadawa) areas lie within 100 $\mathrm{km}$ south of Kano city $\left(12^{\circ} 3^{\prime} \mathrm{N}, 8^{\circ} 32^{\prime} \mathrm{E}, 470 \mathrm{~m}\right.$ a.s.l.) in the Sudan savanna zone of northern Nigeria. The climate has distinct seasonality with a single rainy season which peaks in July and August. Total annual rainfall rarely exceeds $900 \mathrm{~mm}$, and shows great fluctuation from year to year (Fig.1).

The original vegetation of the region has been altered through cultivation, grazing and frequent burning for centuries, and more drastically since the early 1950 s. Thus, the so-called Sudan savanna woodland is now restricted to patches of forest reserves, and much of its vast stretches has been changed mostly to arable land and some degraded savanna in which scrub woodland, low shrubs, and grass scrubland dominate. Common tree species in the general area included Adansonia digitata L., Parkia biglobosa (Jacq.) Benth, Sclerokaya birrea (A. Rich) Hochst, Acacia albida Del, Tamarindus indica L., Vitex doniana Sweet, Combretum nigricans (Guill.) Perr, and Piliostigma thoningi (Schum.) Milne-Redhead. Shrub vegetation was dominated by Acacia ataxacantha DC., Acacia senegal L. Willd., and Dichrostachys glomerata (L.) Chiov. Herbs, abundant especially during the rainy season, included Indigofera hirsuta L., Teprosia purpurea (L.) Pers., Waltheria indica L., and Zonia glochidiata Reich. ex DC. The vine species included Ipomea aquatica Forsk and Leptodonia hastata (Pers.) Decne. The grass and sedge communities were predominantly Andropogon gayanus Kunth, Hyparrhenia and Schizachyrium spp., Pennisetum pedicelatum Trin., Cynodon dactylon (L.) Pers, Eragrostis tenella (L.) and Digitaria gayana (Kunth) Stapf ex Chev. The grasses, mostly about 0.5-1.5 m tall except for A. gayanus, some taller forbs and occasional trees and shrubs, created the general outlook of the study areas.

Before the advent of large-scale irrigated agriculture in the region (pre 1970s), only rainy season food crops (sorghum, maize, upland rice and cowpeas) and cash crops that include groundnuts (peanuts), beniseeds (sesame) and cotton were grown. Now wheat, maize, tomatoes, and other vegetables are also grown in large quantities during the dry season. There were also numerous fruit orchards that are irrigated during the dry seasons. The grass vegetation within these orchards and uncultivated and poorly maintained plots inside crop farms form the refugial habitats for rodents that later migrate into the nearby crop fields.

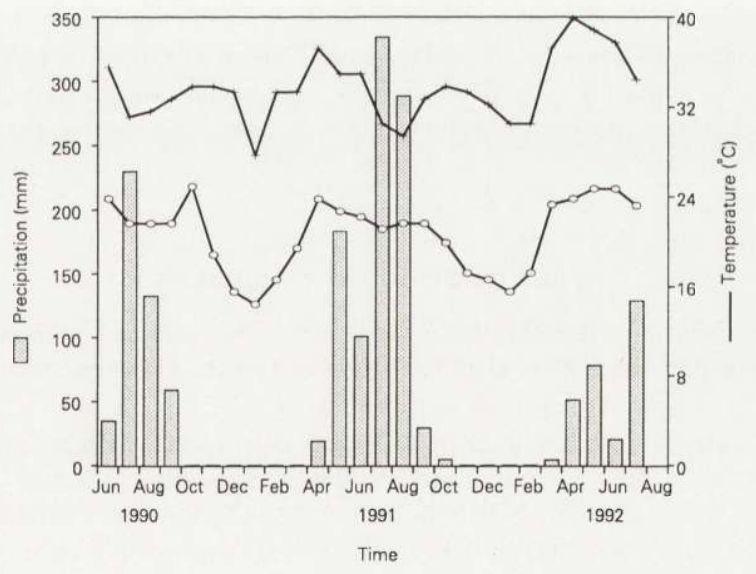

Fig. 1. Climatic data of the Kano District, northern Nigeria, (June, 1990 - July, 1992). Raw data courtesy of the Kadawa Irrigation Research Station, Nigeria. Note the distinct seasonal rainfall pattern. Temperatures are the means of high and low values for the months. 


\section{Analysis of stomach contents}

Rodents of the three species were collected alive using modified Fitch traps (Rose 1994) placed near burrow entrances and across runways in both natural and irrigated sites. Traps were set at multiple trapping plots to reduce the probable effect of spatial bias. Thus, the irrigation site (as used hereafter) is actually a composite of six trapping plots, and the natural, non-irrigated site is a composite of seven trapping plots. Trapping was conducted for two to three days per month or, until the desired sample size for the month was obtained. Animals were necropsied and stomach contents were prepared for quantitative volume estimates according to methods described in Gębczyńska and Myrcha (1966) and Hansson (1970, 1971). Bait (mixed seeds), if present, was usually confined to the cardiac end of the stomach, and thus, easily removed. The contents were washed in warm water, dried and weighed. The material was then diluted with water after being thoroughly homogenized. A small portion of the homogenate was then added to a slide, spread evenly and covered with a cover slip.

From these slides the percent of one visual field (at 100× magnification) covered by individual food items was estimated using a $10 \times 10$ squares ocular grid. Fifteen visual fields were examined for each slide to determine an average value. Food items were identified by comparison with "reference slides" (described in the next section), and recorded as dicots (vegetative), monocots (vegetative), seeds (including cereals and starch), and insects (and other animal matter). For smoother reading these food groups are hereafter simply referred to as dicots, monocots, seeds and insects, respectively. A fifth category of unidentifiable material (usually no more than an average of $5 \%$ by mass of the total food fragments) was noted. No further consideration is given to this group of stomach fragments. Considering the surface area occupied by all food items to be $100 \%$, the percent of each food type in a stomach was estimated by assuming that its proportion in the visual field of the microscope corresponds to its weight proportion (Gębczyńska and Myrcha 1966, Hansson 1970). Experimental tests and discussion on the validity of this assumption are given in Hansson (1970). For a determination of the mean percent food composition of the series of stomachs ( $\mathrm{g}$ for each species in a given season), the diet estimation formula described in Delany and Monro (1986) was used:

$$
\bar{a}=\Sigma(\mathrm{I} a) / \mathrm{T} \times 100
$$

where $\bar{a}$ is the mean contribution of food A to the diet in a particular period, I is the percentage of a sample that was identifiable, $a$ is the percentage contribution of food A to the identifiable fraction of that sample, and $\mathrm{T}=\Sigma[\Sigma(\mathrm{I} a)]$ for all food types in the period considered. Data thus obtained were pooled on monthly bases and transformed using arcsin square root prior to statistical evaluations. The mean percent consumption of food groups of each species was examined by $\chi^{2}$-tests to detect any food selection differences between the sexes. A multiple analysis of variance test (MANOVA) was used to test the differences between species and effects of seasons, sites and their interactions on the mean food groups consumed in both natural and irrigated grass fields. Following the MANOVA, canonical discriminant analysis tests were used to identify those food groups that contributed significantly to the differences among species, sites, seasons and their interactions.

\section{Food and habitat conditions}

For the purpose of food identification described in the last section, "reference slides" were made earlier of potential food items from the study sites, using methods described in Williams (1959) and Hansson (1970). Vegetative plant materials were collected, identified and processed in the laboratory by softening in warm water or lactic acid. The epidermal layers were stripped or scraped off, and other parts of the plant were sliced or simply minced. These were then washed and stained with $1 \%$ haematoxylin solution. Weed and crop seeds as well as insect parts were minced to the same texture as those of the stomach contents. Finally, the materials were mounted on microscopic slides and used for comparison with and identification of food fragments from rodent stomachs.

To evaluate the plant vegetative cover in the habitats and further determine the potential food availability to the rodents in each season, a modified point quadrat sampling method (Goodall 1957) was used. The point quadrat is a non-dimensional quadrat represented by a small point. The sampling 
equipment consisted of ten pins arranged $10 \mathrm{~cm}$ apart on a $1-\mathrm{m}$ long aluminium frame that keeps the pins in a straight line position and perpendicular to the ground surface. The sampler was moved randomly in the study sites until 100 samples (per 1 ha plot) were taken. The procedure was carried out quarterly (during February, May, August and November) both in the natural and irrigated sites. These periods corresponded to the mid-dry season, early rainy season, mid-rainy season, and early dry season, respectively. Plant cover, equal to the fraction of the total pins (expressed in percentage) that touched any part of the plant after the frame was lowered to the ground, was computed using this formula:

$$
\mathrm{C}=\mathrm{f} / \mathrm{T} \times 100
$$

where $\mathrm{C}$ - percent cover of a particular plant species, $\mathrm{f}$ - number of pins that made contact with that plant species (in all samples taken during a given sampling period), and $\mathrm{T}$ - total number of pins in all samples taken during a given period. Mean annual cover for each plant was subsequently computed from values of the four sampling periods.

The effects of site, species, and seasonal changes on plant cover were tested by ANOVA after the values were square-root transformed. The differences in mean values were compared using Ryan-Einot-Gabriel-Welsch multiple range test (hereafter simply referred to as REGWQ test). Qualitative changes in the vegetative matter, such as desiccation of the grasses and the availability of seeds either on the plants or on the ground, were examined only visually. Because data on the nutritive values (such as dry matter content, caloric value and crude protein content) of fodder resources in northern Nigeria abound in the literature (eg Raay 1975), no attempt was made to estimate these variables in the present study.

\section{Results}

More than $90 \%$ of the contents of each stomach could be identified to major groups of food (dicots, monocots, seeds, and insects), a secondary aim of identifying items to species level being achieved in only a few cases. Because no significant differences in dietary selection between the sexes were observed, diet data for males and females were pooled for subsequent analyses.

\section{Arvicanthis}

Seasonal diet selection in Arvicanthis in both natural and irrigated fields is shown in Table 1. During the first rainy season of the study (ie July 1990 to October 1990) in the natural, non-irrigated site, monocots and seeds predominated in the diet. Insect foods were also important, and ranked third. These insects, consumed by all the three species concerned in the present study, included small beetles, termites and early instars of grasshoppers. The insects did not constitute a menace to agricultural production in the area, in contrast to the rodents. In the following dry season, large amounts of dicots were consumed, more than monocots or seeds even though the latter groups remained important also. A similar trend of alternation between monocots (in the wet season) and dicots (in the dry season) as the most important food group for Arvicanthis in the natural fields was observed during the remaining seasons (Table 1). The differences in the proportions of insects in the diet between the wet seasons and dry seasons were very large for Arvicanthis in the natural fields. In the irrigated fields, however, seeds (not dicots or monocots) was the most important diet category, regardless of seasons. Thus, 


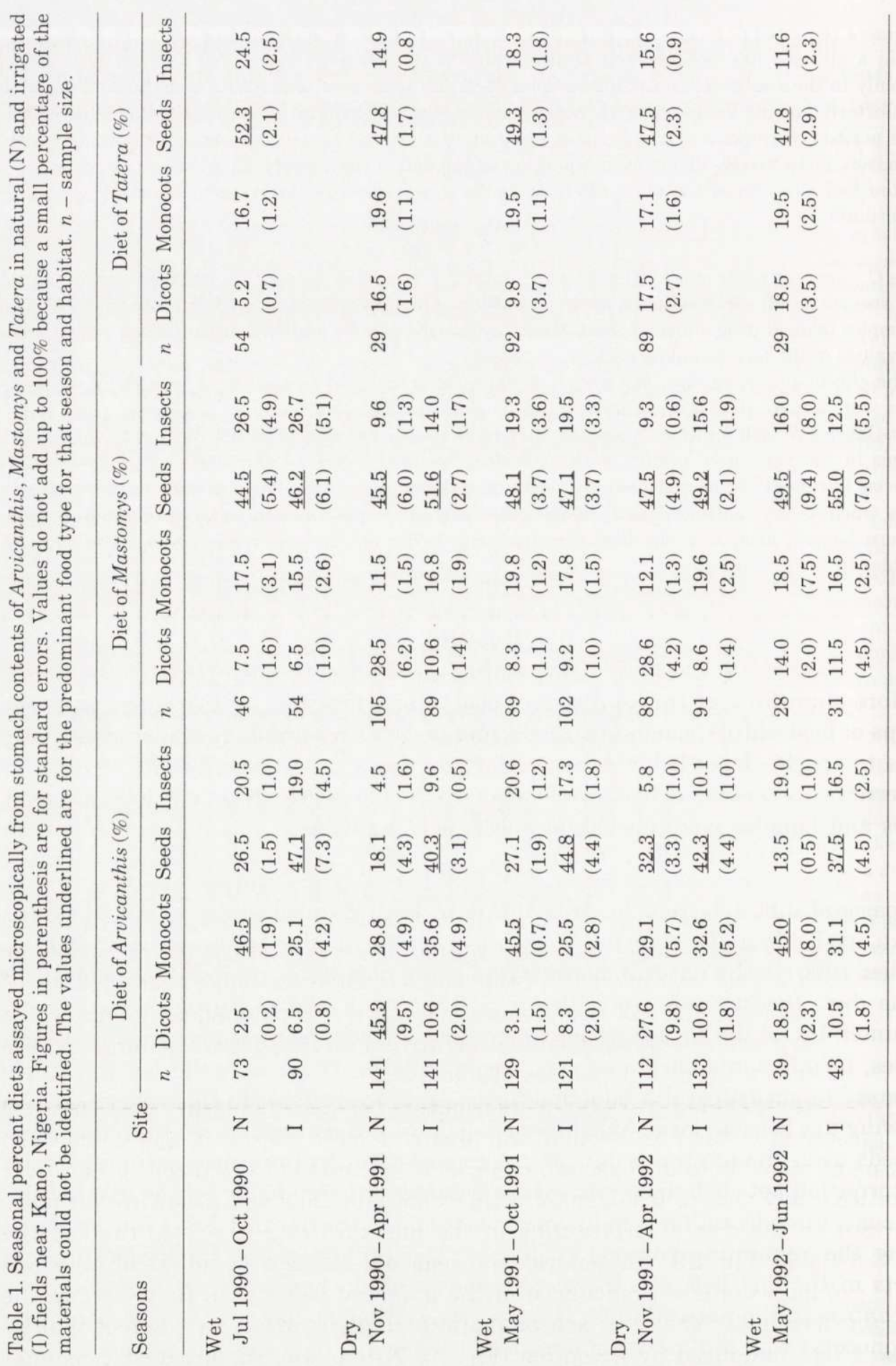


seasonal differences in seeds consumption within the irrigated site were not as profound as in the natural fields. Monocots ranked second in importance for Arvicanthis in the irrigated fields, with the greater amounts being consumed during the dry seasons. Consumption of dicots vegetation in the irrigated fields was generally lower than $10 \%$ during most seasons (Table 1).

\section{Mastomys}

Mastomys had different patterns of food consumption from that of Arvicanthis in both natural and irrigated fields (Table 1). For example, consumption of seeds was always higher in the natural fields throughout the year, accounting for approximately half of the total food intake by mass, a pattern seen in irrigated fields too. Although there were seasonal fluctuations in amounts of insects consumed by Mastomys, overall, the amounts were proportionately higher than those taken by Arvicanthis. Consumption of dicots vegetative matter in the natural fields during the dry seasons was markedly higher than in the wet seasons. This was also the case with Arvicanthis. In the irrigated fields, seeds remained the most important diet group throughout all seasons, even exceeding $50 \%$ of the total foods consumed during the wet seasons of 1991 and 1992 (Table 1). There were hardly any seasonal differences in the seed proportions consumed. Insect foods ranked second in importance, with the proportions being remarkably similar in the wet seasons but showing slight positive effects of irrigation in the dry seasons. Vegetative material of monocots and dicots ranked third and fourth, respectively, with few seasonal differences. Unlike the case of Arvicanthis, no class of food was seriously or consistently enhanced by irrigation in Mastomys (Table 1).

\section{Tatera}

We noted with interest the complete absence of Tatera from areas influenced by irrigation. The species was never trapped throughout the period in which necropsy samples were removed from the fields. Food selection in Tatera in the natural, non-irrigated fields was very similar to that of Mastomys in the same area, ie with nearly half or more of the stomach contents being seeds (Table 1). As with Arvicanthis and Mastomys, more insects were consumed during the rains than in the dry seasons. Slightly more vegetative materials were consumed during the dry seasons than in wet seasons (Table 1).

While data in Table 1 provide the information needed to underpin the statistical tests presented in the next section, the illustrations in Figs 2, 3, and 4 show the patterns of monthly (and seasonal) changes in the diets of the three species over the entire study period. It is apparent that both monocots and dicots are far more important in the diet of Arvicanthis in the natural fields (Fig. 2A) than in the irrigated fields (Fig. 2B). In general, the seasonal changes in intake of all kinds of food groups were less pronounced in the irrigated fields than they were in the natural grass fields. The same seasonal effects apply to Mastomys, except that its diet was less enhanced by irrigation (Fig. 3). Tatera was the greatest consumer 


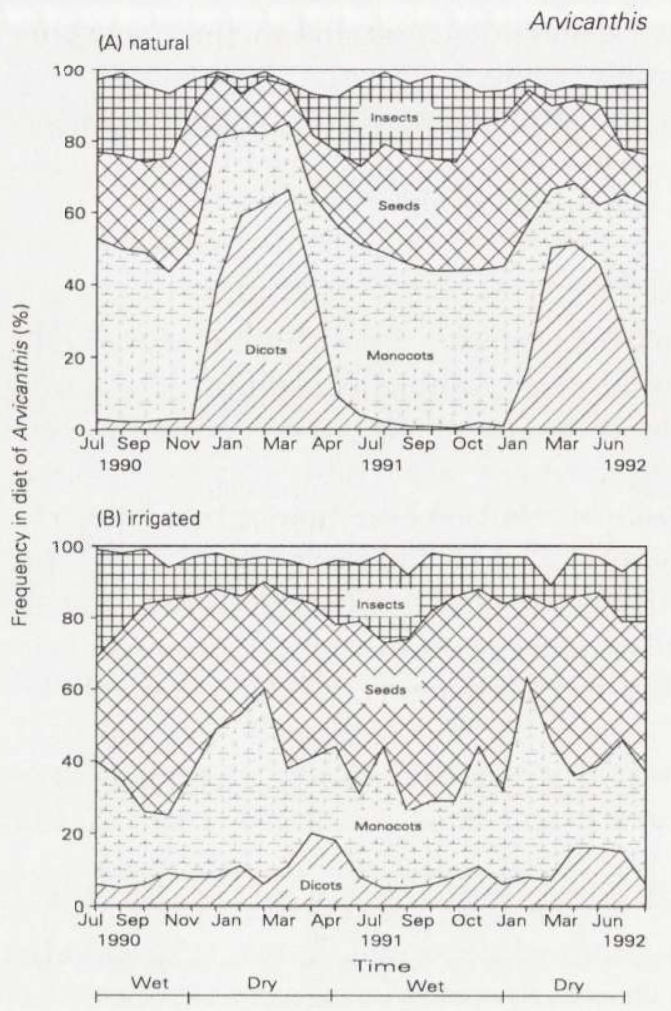

Fig. 2. Diet of Arvicanthis as determined by microscopic analysis of stomach contents in both natural (A) and irrigated (B) areas near Kano, northern Nigeria, during July 1990 to June 1992. The white area at the top of the figure is the remainder, ie unidentified food items, which were usually $1-5 \%$ of contents. "Wet" and "Dry" refer to wet and dry seasons.

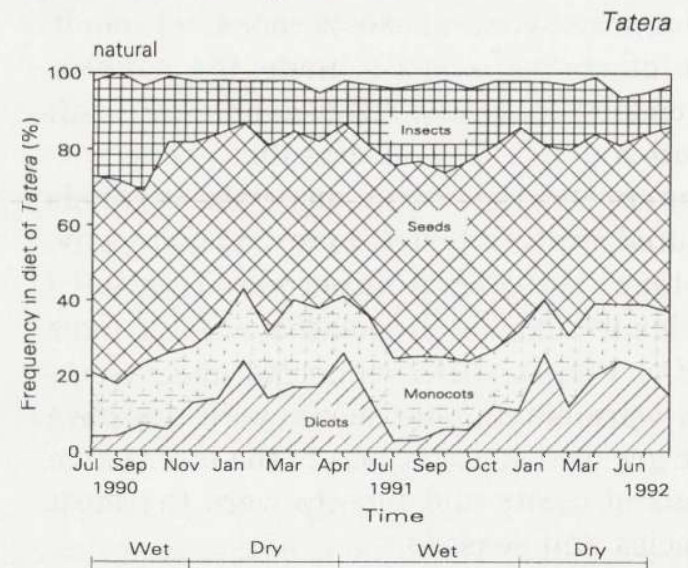

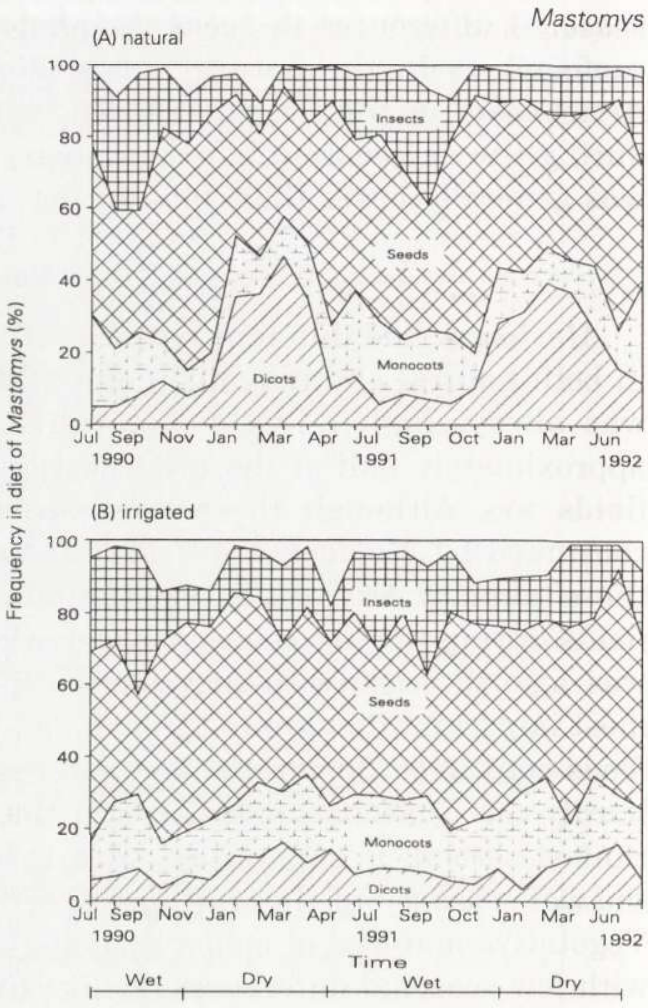

Fig. 3. Diet of Mastomys as determined by microscopic analysis of stomach contents. See Fig. 2 for explanations.

Fig. 4. Diet of Tatera as determined by microscopic analysis of stomach contents in natural areas. See Fig. 2 for explanations. 
of seeds and insects, and showed the least seasonal fluctuations in the amounts consumed (Fig. 4).

\section{Statistical analysis}

Results of MANOVA (Table 2) indicated that the food types eaten were significantly affected by site and season. There were also significant species differences. The interactive effects of site and species, seasons and species, and site and seasons on the type of food eaten were significant too (Table 2).

Table 2. Results of a three-factor MANOVA testing the effects of sites (natural and irrigated fields), species (Arvicanthis, Mastomys and Tatera) and seasons (wet and dry) and their interactions on the consumption of foods by the three species of rodents near Kano, Nigeria.

\begin{tabular}{lccccc}
\hline Source & $\begin{array}{c}\text { Hypothesis } \\
\text { df }\end{array}$ & $\begin{array}{c}\text { Error } \\
\text { df }\end{array}$ & $F$ & $\begin{array}{c}\text { Wilk's } \\
\text { lambda }\end{array}$ & $p$ \\
\hline Sites & 4 & 92 & 11.7 & 0.6626 & $<0.001$ \\
Species & 8 & 184 & 21.9 & 0.2622 & $<0.001$ \\
Seasons & 16 & 281 & 5.8 & 0.4177 & $<0.001$ \\
Sites $\times$ Species & 4 & 92 & 6.3 & 0.7825 & $<0.001$ \\
Species $\times$ Seasons & 32 & 340 & 1.4 & 0.6190 & $<0.05$ \\
Sites $\times$ Seasons & 16 & 281 & 2.8 & 0.6335 & $<0.001$ \\
Sites $\times$ Species $\times$ Seasons & 16 & 281 & 0.7 & 0.8742 & 0.6 \\
\hline
\end{tabular}

Canonical discriminant analysis test results indicated that the significant differences in types of foods consumed as detected by MANOVA corresponded to the relative availability of the foods between sites, seasons, and preference of the animal species (Table 3). With respect to site, dicots and monocots had high positive correlations, whereas both seeds and insects had negative correlations with the vegetative materials (Table 3 ). The proportion of insects consumed made no significant contribution to the effect of site. Monocots made the highest contribution to the significant differences caused by rodent species, and had high positive correlation with other food categories eaten. The insects diet group was marginally significant in its contribution to species effect on types of foods consumed. Both dicots and insects contributed highly, though in an opposite way, to the significant seasonal effect on food intake. Thus, when dicots were consumed in large quantities in the natural grass fields during the dry season, insects were in short supply, and conversely in the rainy season when monocots and insects became available, significantly less dicots were eaten. The seeds, with negative coefficient and correlation values, made the greatest contribution to the interactive effect of site and species. The contributions of dicots and insects were the most important for the interactive effects of species and seasons. 
Table 3. Standardized discriminant canonical coefficient (Coeff), within canonical correlations (Corr), $F$ values, and significance levels $(p)$ for differences in diet selection among three rodent species, between sites and seasons, and their interactions in fields near Kano, Nigeria.

\begin{tabular}{|c|c|c|c|c|}
\hline Food groups & Coeff & Corr & $F$ & $p$ \\
\hline \multicolumn{5}{|l|}{ Sites } \\
\hline Dicots & 1.7 & 0.3 & 17.4 & $<0.001$ \\
\hline Monocots & 1.7 & 0.6 & 5.7 & $<0.05$ \\
\hline Seeds & 0.2 & -0.7 & 27.7 & $<0.001$ \\
\hline Insects & -0.1 & -0.1 & 0.7 & 0.4 \\
\hline \multicolumn{5}{|l|}{ Species } \\
\hline Dicots & 0.4 & 0.1 & 1.7 & $<0.05$ \\
\hline Monocots & 1.5 & 0.7 & 72.3 & $<0.01$ \\
\hline Seeds & -0.4 & -0.5 & 42.4 & $<0.001$ \\
\hline Insects & -0.5 & -0.1 & 3.0 & 0.05 \\
\hline \multicolumn{5}{|l|}{ Seasons } \\
\hline Dicots & 0.9 & 0.5 & 8.9 & $<0.001$ \\
\hline Monocots & 0.8 & 0.1 & 0.5 & 0.7 \\
\hline Seeds & 0.1 & -0.1 & 0.3 & 0.8 \\
\hline Insects & -1.1 & -0.8 & 22.6 & $<0.001$ \\
\hline \multicolumn{5}{|c|}{ Sites $\times$ Species interaction } \\
\hline Dicots & -1.6 & 0.1 & 0.2 & 0.6 \\
\hline Monocots & -0.5 & 0.6 & 10.2 & $<0.01$ \\
\hline Seeds & -2.5 & -0.7 & 15.6 & $<0.001$ \\
\hline Insects & -1.1 & 0.1 & 0.2 & 0.6 \\
\hline \multicolumn{5}{|c|}{ Species $\times$ Seasons interaction } \\
\hline Dicots & 1.5 & 0.7 & 2.6 & $<0.05$ \\
\hline Monocots & 0.4 & -0.4 & 1.4 & 0.1 \\
\hline Seeds & 0.6 & 0.1 & 0.1 & 0.2 \\
\hline Insects & -0.6 & -0.7 & 2.6 & $<0.05$ \\
\hline \multicolumn{5}{|c|}{ Sites $\times$ Seasons interaction } \\
\hline Dicots & -1.4 & -0.8 & 9.4 & $<0.001$ \\
\hline Monocots & 0.8 & 0.8 & 7.9 & $<0.001$ \\
\hline Seeds & -0.6 & 0.1 & 0.8 & 0.5 \\
\hline Insects & 0.1 & 0.4 & 2.4 & 0.05 \\
\hline
\end{tabular}

Cover and herbage conditions

In all, 86 plant species (excepting cultivated crops) were recorded in both natural and irrigated sites. Grasses in the natural fields were very important in their mean annual proportion to the total vegetation cover (Table 4), and hence to monocots diet (Table 1). Results of ANOVA showed no significant site or seasonal effects on the amount of vegetation cover, but the species effect was significant (ANOVA: $F=3.87, p<0.1$ ); hence few (mostly grass) species dominated the vegetative cover. The interaction of site $\times$ species was also significant (ANOVA: 
Table 4. Selected plant species constituting the highest percent vegetative cover in the natural and irrigated fields near Kano, northern Nigeria. The asterisks $\left(^{*}\right)$ refer to those seasons in which percentages of vegetative cover were significantly high among other species (REGWQ test, $p<0.05$ ). $\mathrm{AD}$ - annual dicot, AM - annual monocot, PS - perennial shrub, PM - perennial monocot, PT perennial trailer, AP/D - annual/perennial dicot, and A/PM - annual/perennial monocot.

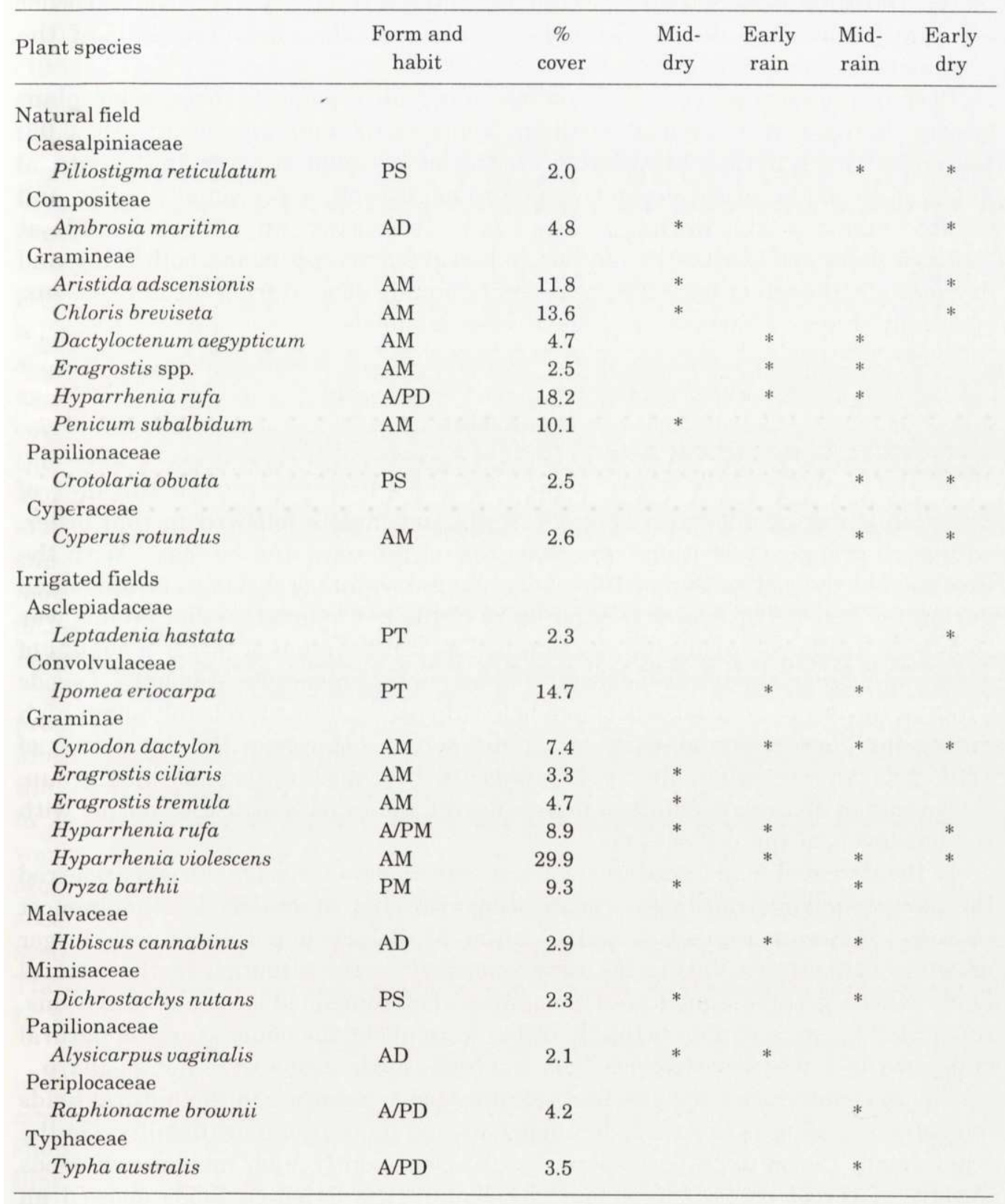


$F=4.89, p<0.1$ ). In the irrigated fields, grasses were also important. Overall results showed that nearly $80 \%$ of the total mean annual vegetation cover was dominated by 15 plant species, nearly half of which were members of the family Gramineae (Table 4). The other species, which included annual and perennial dicot plants, constituted the second large fraction of the vegetative cover. About 60 other less important species, not listed here, made up the remaining half of the vegetative cover.

Despite the lack of seasonal variation in overall vegetative cover, some plant species (marked with single asterisks in Table 4) did show significant $(p<0.05)$ seasonal changes in their contributions to the total vegetative cover. In the natural fields, most of the green vegetative materials, excepting perennial grasses and shrubs, were available during the rains only. In contrast, the irrigated fields at Kadawa sustained grasses in addition to cereal food crops during both rainy and dry seasons, though at least $20 \%$ were dry (standing dead) during the dry seasons, especially in places farther away from water channels.

\section{Discussion}

In the natural grass fields, monocots consistently dominated the diet of Arvicanthis during the rains (Fig. 2). Seeds and insects followed in that order, with each group constituting more than $20 \%$ of the total diet by mass. With the exception of the wet season of 1992, very small amounts of dicots were consumed during the rains. The seasonal importance of the two vegetative diet groups was somewhat reversed during the dry seasons, ie, consumption of larger amounts of dicots, and lesser, though still substantial, amounts of monocots. Amounts of seeds eaten in the dry seasons also declined below the wet seasons levels (although high during the harvest period, early in the dry season). However, the dry season of 1991 was an exception, for seeds made up the most important diet group. Consumption of large amounts of insects during the rains contrasted sharply with the low levels of the dry seasons.

In the irrigated fields, seeds were clearly the dominant food materials preferred the year around by Arvicanthis, constituting about half of total foods eaten in most seasons. Monocots ranked second in order of dietary importance, with larger amounts being eaten during the rains, contrary to the situation in the natural fields where greater amounts of monocots were consumed in the wet seasons. Amounts of insects eaten during the rains were about the same as in the natural site, but the dry season declines from the highs of the rains were not as sharp.

The seasonal fluctuations in food selection for Arvicanthis in the natural fields indicated a readiness to switch diet depending on its seasonal availability. On the other hand, the pattern of consumption of consistently high amounts of seeds (mostly of cereal crops) throughout the year in the irrigated fields showed an opportunistic tendency, and thus, indicated its potential as pests of cultivated 
crops Another interesting feature of its dietary selection was that even larger amounts of monocots (mostly vegetative wheat) were consumed in the dry seasons than in the wet seasons, a further indication of its destructive potential on growing cereal crops. Thus, the diet of Arvicanthis was enhanced by irrigation in terms of selection of seeds, monocots, and, to a lesser extent, of insects.

The diets of Arvicanthis in northern Nigeria reported in Rabiu and Fisher (1989) from similar sites within the same ecoclimatic zone as the natural sites in the present study, showed a similar pattern of seasonal fluctuation in terms of the major food groups consumed. However, the seeds in that study were not as important in their contribution to the overall diet as in the present case, and also the proportions of insect diet recorded were greater than those recorded in the present study.

Thus, in northern Nigeria, seeds predominated in the diet of Arvicanthis in the later part of the rains, and dicots during the late dry seasons. In the natural fields, a good supply of monocots was available only in the wet season. During the dry season period the only source of fresh monocots was from perennial grasses, such as A. gayanus, which was not an important plant species in terms of vegetative cover but probably was a major source of moist food. It was not surprising, there ore, that large amounts of dicots were consumed in the dry seasons. Rabiu and Fisher (1989) observe that the importance of seeds and monocots in the diet of Aricanthis in northern Nigeria was less than that in east Africa, findings also supported in the present study. In Kenya, the diet of Arvicanthis is mainly of monocots during the late dry seasons (rather than dicots as in the natural fields of northern Nigeria), and of seeds in the later part of the rains up to the early part of the dry season (Taylor and Green 1976, Delany and Monro 1986).

In the natural fields, Mastomys rated higher than Arvicanthis in respect to proportion of seed intake, with a mean of nearly $50 \%$ of its food made of seeds. More insect food was eaten during the rains (as was the case with Arvicanthis), the periods of greater abundance. Vegetative materials were not as important as in Aricanthis even though dicots made up a substantial part of the foods that were eaten during the dry seasons. The lower significance of vegetative foods in Mastomys may be due to its apparently greater preference and search effort for seeds than Arvicanthis. In the irrigated fields Mastomys consumed slightly more seeds (by about $2-3 \%$ ) throughout the year than it did in the natural grass fields. Therefore, the present study showed that the diet of Mastomys was less enhanced by irrgation than that of Arvicanthis.

Also in the natural site, Tatera (already noted as never been trapped from the irrigaed site) showed high preference for seeds with little seasonal fluctuation in amourts eaten, similar to that of Mastomys. Amounts of insects eaten, though showing declines during the dry seasons, were generally proportionately larger than in either Arvicanthis or Mastomys. Larger amounts of dicots were consumed during the dry seasons than in the wet seasons. Seasonal differences in the 
selection of monocots were not significant. In general, vegetative foods were less important to Tatera than to Arvicanthis but similar to Mastomys.

All three species showed great preference for seeds but Tatera was the greatest consumer of seeds and insects among the three species in the natural grass fields. These findings are consistent with results from other similar studies. From southern Africa, Swanepoel (1980) reports that seeds were an important constituent in the diet of Mastomys, being present in all stomachs examined and forming the major dietary component in 93\% of those stomachs. Abramsky (1983) and Bar et al. (1984) note the efficiency of gerbilline rodents in active search and use of seeds, including those buried below the ground. Happold (1987) also refers to the savannah Gerbil in Nigeria as granivorous. In the present study, the high proportions of mainly crop seeds eaten by both Mastomys and Tatera in the natural fields during the late dry seasons (when seeds were in relatively short supply) may have come from the soil seed bank, supplies stored in caches, or secured from nearby stores and granaries. Another explanation may be that Mastomys manages to continue to find seeds by ranging widely over open ground during the dry seasons when the seeds become less common (Taylor and Green 1976).

Given the differences in the dietary selection in the three species, it was not surprising that the results of MANOVA showed significant differences between species and effects of sites, seasons, as well as that of their interactions on the diet consumption. When comparing the intake of seeds, Mastomys and Tatera seem to be the more serious potential pests than Arvicanthis. However, the lower population levels of Tatera and Mastomys (S. Rabiu and R. K. Rose, in prep.) and, as already mentioned, the poor adaptation of Tatera to the irrigated fields (the irrigation scheme has been operational in northern Nigeria for more than two decades now) put them at lower potential pest statuses than the physically and numerically much larger Arvicanthis.

The significance of diet, especially the role of plant products that stimulate reproduction in rodents, has been extensively discussed in the literature (Gautun 1975, Delany and Monro 1986). Although that subject lies outside the scope of this paper, suffice it to say that reproduction in Arvicanthis and Mastomys was continuous in the irrigated fields of northern Nigeria but was discontinuous (seasonal) in the natural fields, a fact likely related to the quality and availability of food at the two sites. Vegetation is an important source of cover and food to rodents (Delany and Monro 1986). Indeed, we observed drastic declines in population levels when the grasses in our demographic study grids were slashed for routine management purposes. The present study also provides evidence of the role of vegetation in food supply for these rodents.

Neither the natural nor irrigated fields showed any significant seasonal differences in the amounts of vegetation cover throughout the year (Table 4). However, there were significant seasonal changes in the contributions of individual plant species to the total cover. It appeared that the most important difference in vegetation between the two study sites was in terms of the vegetation 
quality. In the natural site most of the grass and herb vegetation dried up during the dry season.

In conclusion, we note the importance of seeds in the diets of the three rodents. In fact, seeds were the most important food type for Mastomys in both sites and for Tatera in the natural sites. For these two species, high consumption of seeds even during the late dry season shortages (in the natural site) was apparently sustained by eating from caches, through active ground searches, or possibly, depredation from granaries. Arvicanthis showed the highest tendency to switch diets as availability fluctuated in different seasons. It consumed greater amounts of dicots during the late dry season (a period of seeds shortages in the natural fields), but increased its seeds consumption to a significant level in the irrigated fields over the same period. Thus, all three rodents showed greater preferences for seeds over other food items. Monocots and insects followed as important foods during the wet season in the natural fields and throughout the year in the irrigated fields. The field assessment of vegetation and its dynamics provided the knowledge of what was available and of its quality to rodents as potential food. The present study has shown considerable similarity and varying degrees of overlap in the foods of the three species.

Acknowledgements: We are grateful to The Rockefeller Foundation for financial support, and Old Dominion University and Bayero University, Kano, Nigeria for administrative support. We also thank the farmers and officials of the Kano River Project, Nigeria, for their cooperation, and Messrs A. Aliyu, Mal. A. Garko, M. M. Malam and M. N. Nwaiko for assisting us with field work.

\section{References}

Abramsky Z. 1983. Experiments on seed predation by rodents and ants in the Israeli Desert. Oecologia 57: 328-332.

Bar Y., Abramsky Z. and Gutterman Y. 1984. Diet of the gerbilline rodents in the Israeli Desert. Journal of Arid Environments 7: 371-376.

Delany M. J. 1986. The ecology of small rodents in Africa. Mammal Review 16: 1-41.

Delany M. J. and Monro R. H. 1986. Population dynamics of Arvicanthis niloticus (Rodentia: Muridae) in Kenya. Journal of Zoology 29: 85-103.

Field A. C. 1975. Seasonal changes in reproduction, diet and body composition of two equatorial rodents. East African Wildlife Journal 13: 221-236.

Funmilayo O. and Akande M. 1977. Vertebrate pests of rice in southwestern Nigeria. PANS 23: $38-48$.

Gautun J. C. 1975. Periodicite de la reproduction dequelques rongeurs d'une savane preforestiere due centrede la Cote-d'Ivoire. La Terre et La Vie 29: 265-287.

Gębczyńska Z. and Myrcha A. 1966. The method of quantitative determining of the food consumption of rodents. Acta Theriologica 16: 385-390.

Ghobrial L. I. and Hodieb A. S. K. 1982. Seasonal variations in breeding of the Nile rat (Arvicanthis niloticus). Mammalia 46: 319-332.

Goodall D. W. 1957. Some consideration in the use of point quadrat methods for the analysis of vegetation. Australian Journal of Biological Science 5: 1-41.

Hansson L. 1970. Methods of morphological diet micro-analysis in rodents. Oikos 21: 255-266.

Hansson L. 1971. Small mammal food, feeding and population dynamics. Oikos 22: 183-198. 
Happold D. C. D. 1987. The mammals of Nigeria. Clarendon Press, Oxford: 1-402.

Hubert B., Gullion D. and Adam F. 1981. Annual diet cycle of the three principal species of rodents (Rodentia: Gerbillidae and Muridae) from Bandia (Senegal). Mammalia 45: 1-20.

Leirs H., Verheyan W., Michiels M., Verhagen R. and Stuyck J. 1989. The relation between rainfall and breeding seasons of Mastomys natalensis (Smith, 1834) in Morogoro, Tanzania. Annals of the Society of Zoology 119: 59-64.

Neal B. R. 1977. Reproduction of the Multimammate rat, Praomys (Mastomys) natalensis (Smith), in Uganda. Zeitschrift für Säugetierkunde 42: 221-231.

Neal B. R. 1982. Reproductive biology of three species of gerbils (Genus Tatera) in East Africa. Zeitschrift für Säugetierkunde 47: 287-296.

Neal B. R. 1984. Seasonal feeding habits of small mammals in Kenya. Zeitschrift für Säugetierkunde 49: $226-234$.

Perrin M. R. 1980. The feeding habits of two co-existing rodents Rhabdomys pumilio (Sparrman 1784) and Otomys irroratus (Brants 1827) in relation to rainfall and reproduction. Acta Oecologia 1: 71-89.

Poulet A. R. and Poupon H. 1978. L'invasion d'Arvicanthis niloticus dans le Sahel Senegalais en 1975-76 et sesconsequences pour la strate ligneuse. La Terre et LaVie 32: 161-193.

Raay H. G. T. van. 1975. Rural planning in savanna region. University Press, Rotterdam: 1-181.

Rabiu S. and Fisher M. 1989. The breeding season and diet of Arvicanthis in northern Nigeria. Journal of Tropical Ecology 5: 375-386.

Rose R. K. 1994. Instructions for building two live traps for small mammals. Virginia Journal of Science 45: 151-157.

Rosevear D. R. 1969. The rodents of West Africa. British Museum (Natural History), London: 1-601.

Sheppe W. 1972. The annual cycle of small mammal populations on a Zambian floodplain. Journal of Mammalogy 53: 445-460.

Swanepoel C. M. 1980. Some factors influencing the breeding seasons of Praomys natalensis. South African Journal of Zoology 15: 95-98.

Taylor K. D. 1968. An outbreak of rats in agricultural areas of Kenya in 1962. East African Agricultural and Forestry Journal 34: 66-77.

Taylor K. D. and Green M. G. 1976. The influence of rainfall on diet and reproduction in four African rodent species. Journal of Zoology 18: 367-389.

Williams O. 1959. Food habits of the Deer Mouse. Journal of Mammalogy 40: 415-419.

Received 3 April 1996, accepted 20 January 1997. 